OPEN ACCESS

Edited by:

Monika Urban,

University of Bremen, Germany

Reviewed by:

Simon Egbert,

University of Hamburg, Germany

Andreas Baumeister,

University of Bremen, Germany

*Correspondence:

Jenny Melind Bergschöld

jenny.bergschold@ntnu.no, jenny.bergschold@gmail.com

Specialty section: This article was submitted to

Sociological Theory,

a section of the journal

Frontiers in Sociology

Received: 30 November 2017

Accepted: 15 February 2018

Published: 09 April 2018

Citation:

Bergschöld JM (2018) Configuring Dementia; How Nursing Students

Are Taught to Shape the

Sociopolitical Role of

Gerontechnologies.

Front. Sociol. 3:3.

doi: $10.3389 /$ fsoc.2018.00003

\section{Configuring Dementia; How Nursing Students Are Taught to Shape the Sociopolitical Role of Gerontechnologies}

\author{
Jenny Melind Bergschöld* \\ Institute for Interdisciplinary Studies of Culture, Norwegian University of Science and Technology, Trondheim, Norway
}

This article contributes to the discussion on the materiality of age and aging in this special issue by presenting a case that illustrates how nursing students are trained to shape gerontechnologies in ways that have sociopolitical consequences for older adults with dementia who are aging at home. Drawing on ethnographical fieldwork and grounded theory, I deliberately stage a dialog between STS theory on technology, and relational approaches to the social study of dementia in an analysis of a lecture where master students in a university nursing program learn about gerontechnology and dementia. I identify inability to purposively use technology, recalcitrance, and attentiveness as three problematic behaviors that are described as typical for older adults with dementia who are aging at home, and selection and placement of gerontechnologies as two ways in which the nursing students are taught to delimit this behavior by material means. I show how selection and placement of gerontechnologies are means by which care professionals shape gerontechnologies in ways that can disempower older adults who are aging at home, and I show how the educators draw on a biomedical understanding of dementia to accomplish a link between disempowering, and caring for older adults with dementia. I argue that care professionals practices of shaping gerontechnologies can be understood as empirical sites where care professionals exercise power over older adults with dementia who are aging at home by sociomaterial means. I conclude that there is a continued need for studies of gerontechnologies that stage analytical dialogs between STS theory and understandings from other fields with longer traditions of studying processes of aging, to further elucidate how gerontechnologies can matter to older adults and the experience of aging.

Keywords: gerontechnology, dementia, mediation, intermediaries, configuration, user representations, welfare technology

\section{INTRODUCTION}

Demographic ageing is believed to lead to a future crisis for healthcare systems and welfare states because the increased demand of healthcare services will put financial strain on welfare states where healthcare and eldercare is heavily subsidized. Particularly since there is also an increasing shortage of caregivers for the elderly and registered nurses, as well as other types of healthcare professionals (Broadbent et al., 2009; Nye, 2009). 
In the context of the challenges posed by demographic aging, technological innovation has emerged as a key theme as nation states have sought for solutions (Östlund, 2004; Neven, 2011; Cagnin et al., 2012; Mort et al., 2012; Peine and Herrmann, 2012; De Smedt et al., 2013). Innovations that enable older adults to age at home are usually referred to internationally as gerontechnologies (Graafmans et al., 1998; Charness and Schaie, 2003; Joyce and Loe, 2010; Sixsmith and Gutman, 2013).

One of the key issues that gerontechnologies are meant to solve in relation to demographic aging is dependence on long-term institutional care. As Topo, 2009 points out, this is partly because a dramatic increase in demand is believed to create unsustainable financial problems for nation states, but also because older adults tend to express a will to remain in their homes for as long as possible (Wang and Moyle, 2005; Pekkarinen et al., 2006). Because the risk of dementia increases with advancing age, and dementia traditionally leads to long-term institutional care (Pekkarinen et al., 2004, 2006; Wang and Moyle, 2005), demographic aging is predicted to also mean a considerable increase in the number of people in need of institutional care unless a solution can be found (Gray et al., 2008). The prevalence of dementia is $4.2 \%$ for people aged $70-74,8.6 \%$ for people aged $75-79,13 \%$ for people aged 80-84 and $25.3 \%$ for people aged $85-89$ (World Economic and Social Survey, 2007). As Topo, 2009 points out, this means that the premise that gerontechnologies can enable older adults to age safely in their own homes is inextricably tied to the understanding that this also applies to older adults with dementia. However, the social study of gerontechnologies is still an emerging field (Östlund, 2004; Joyce and Mamo, 2006; Peine et al., 2015), and so far only little is known of how gerontechnologies shape the experience of ageing with dementia.

In Norway, the political ambition is to achieve a nationwide implementation of gerontechnologies into municipal services to support aging in place despite mental or physical disability by 2030. As part of the national program for the implementation of gerontechnologies, 17 out of Norway's 426 municipalities have implemented educational showrooms where local care professionals facilitate the implementation of gerontechnologies by teaching visitors about the benefits of gerontechnologies (Helsedirektoratet, 2012). Thus, the realization of the implementation of gerontechnologies into services has, at least in part been delegated to care professionals whom have been tasked with the role of educators. All of these showrooms are open to the public and attract visits from a variety of members of the public from all over Norway. A few of these showrooms have specialized on dementia. In these showrooms, the educators teach care professionals how they can select and install gerontechnologies for older adults with dementia who are aging at home.

Norway has a 150-year long political tradition of holding the welfare state responsible for the psychosocial and socioeconomic well-being of all members in Norwegian society (Schiøtz, 2003). Contemporary Norwegian policies that describe the rights for people with mental disabilities like dementia build on social and cultural gerontological research. They privilege relational understandings of mental disabilities over biomedical perspectives. This means that the welfare state is responsible for the provision of services, including adaption of the individuals' home environment, that empower care recipients, including individuals with mental disabilities like dementia, by increasing the individuals possibility to retain their democratic rights to equal treatment and participation in society (NOU, 2011).

In the context of demographic aging, this political ideal has shaped Norwegian policy on gerontechnologies. In Norway, gerontechnologies are referred to as welfare technologies. This is a political term that specifies the work that gerontechnologies are supposed to do in the context of services provided to citizens by the Norwegian welfare state in terms of how gerontechnologies are supposed to provide benefits to those services, as well as the citizens who receive them.

This definition specifies that gerontechnologies should contribute to the "increased safety, social inclusion, mobility and physical and cultural activity, as well as increase the individuals' possibility to manage everyday life on their own despite decreased psychological or physical capacities" (NOU, 2012, p. 99).

Thus, the production of social equality and empowerment for Norwegian citizens with mental disabilities like dementia has been made part of the role that gerontechnologies are supposed to fill in Norwegian society. This is an ambitious goal, particularly when considered in relation to previous research in the fields of STS and social studies of dementia. STS has a long tradition of showing that materiality is not "innocent," and the claim that matter matters in relational sociopolitical terms because it can perpetuate or disrupt the production of social inequality in society is arguably the greatest contribution that STS has made to the social sciences (Marres, 2013). These studies illustrate how the sociopolitical roles that technologies will play, meaning how they will matter in sociopolitical terms, continues to be shaped by people long after an artifact has left the factory [see Oudshoorn and Pinch (2003) ch 1 for a comprehensive overview]. Meanwhile, relational approaches to the study of dementia have a long tradition of showing how dementia care is often more controlling than empowering of people with dementia (Fox, 1995). This literature shows that practices of care can be understood as sociopolitical powerstruggles between care professionals and older adults with dementia, where the latter are often disempowered (Bartlett and O'Connor, 2007; Brittain et al., 2010). Thus, it cannot be assumed that educators that teach nursing students how to use gerontechnologies as they care for older adults with dementia are shaping the technology in ways that perpetuates the political ideals attached to welfare technologies. Nor can it be assumed that the way these gerontechnologies are shaped will not matter to older adults with dementia who will be the target of caring practices modeled after these instructions.

In the face of this ambitious goal, I explore the role of Norwegian educators who work in demonstrational showrooms and teach future nurses, as well as other visitors, what older adults with dementia who are aging at home need from gerontechnology. Throughout this exploration, I ask: How are the educators teaching the nursing students to shape gerontechnologies as part of caring for older adults with dementia, and how can this way of shaping gerontechnologies matter to 
older adults? Until very recently the dialog between STS and relational approaches to dementia has been almost non-existent (Joyce and Mamo, 2006; Joyce et al., 2017). One implication is that STS researchers have tended to overlook the role of care professionals in the study of gerontechnologies. Another is that social studies of power struggles between care professionals and older adults with dementia have tended to disregard how care professionals can shape gerontechnology in ways that matter to the sociopolitical roles they play in the lives of older adults who are aging at home. By contrast, I will deliberately stage a dialog between STS and relational approaches to the study of dementia. I will accomplish this dialog by conducting an empirical analysis of how the technology is being shaped by drawing on analytical concepts and ideas from STS. Specifically, "configuring the user” (Woolgar, 1990), User representations (Akrich, 1995), and Mediation (Schot and De la Bruheze, 2003), as well as the notion that materialities can matter to users in sociopolitical terms (Winner, 1980). Thereafter I will interpret the results of this by drawing on concepts and understandings from relational approaches to dementia, specifically "personhood" (Kitwood, 1997) and "citizenship" (Bond, 1992; Harding and Palfry, 1997; Lyman, 1998; Gilleard and Higgs, 2001). My aim in staging this dialog is to see whether these two approaches can complement each other analytically, and to try to elucidate the potentiality of further dialog between STS and relational understandings of dementia.

\section{HOW CONFIGURATIONS, USER REPRESENTATIONS, AND MEDIATION MATTERS}

The notion that users can be configured (Woolgar, 1990) is central to STS research that is concerned with how technologies delimit or afford peoples actions (Oudshoorn and Pinch, 2003). In conceptual terms, configuring the user refers to processes where the identities of putative users to technologies are defined and constraints are put upon their likely future actions by material means (Woolgar, 1990). For instance, very small screws often secure battery hatches on children's toys. Such battery hatches may be understood as an attempt by the designer to ensure that very small children will not be able to remove and swallow batteries. The tiny screws are a material constraint on the toy that configures the user by shaping the space of agency available to the person who wants to open the hatch. This person will require access to a screwdriver of the right size, as well as a sufficiently well-developed hand-eye coordination and motor capacity to successfully remove the very small screw. While this does not mean that no small child will ever be able to open the hatch, it does decrease the likelihood that they will be able to do so. Consequently, to say that putative users can be configured by material means does not mean to imply that the future actions of those putative users are determined in any final way. Technology users frequently act in ways that are unanticipated by those who are trying to configure them. However, configurations can nevertheless shape users spaces of agency in ways that makes it difficult to act outside of the imagined scenario that the configuration is built on, or be someone else than the designer intended. In this sense, user representations (Akrich, 1995), meaning imagined identities of putative technology users, can come to matter in configurations (Oudshoorn and Pinch, 2003).

In STS, the term mediation (Schot and De la Bruheze, 2003) implies the shaping or re-shaping of materialities like technologies by actors who are not designers or users. Mediation is characterized by the mutual articulation and alignment of product characteristics and user requirements, that occurs as the characteristics of technologies and putative user's needs are defined, constructed and linked (Schot and De la Bruheze, 2003). Intermediaries (Pinch, 2003) can construct user representations by acting or speaking on behalf of putative users in relation to their needs or desires (Oudshoorn and Pinch, 2003). In similarity to designers, intermediaries can configure users, however, they means by which they do so differ from designers' means of configuring users. For instance, Pinch (2003) showed how a traveling salesman mediated the Minimoog synthesizer by forging a relationship with the designers and convincing them that he knew what consumers wanted and needed. Thus, while designers shape the technology "from scratch," intermediaries work from a version of the technology that already exist and use other means to shape it. The Minimoog salesman used his experiences of consumers to become a trusted advisor on what "the market" would pay for (Pinch, 2003). Thus, mediation (Schot and De la Bruheze, 2003) is an innovative activity that can occur when intermediaries (Pinch, 2003) draw on the means and space of agency available to them to speak and act on behalf of users in order to shape the technology into a particular version of itself. As part of this process, intermediaries (Pinch, 2003) can configure (Woolgar, 1990) those users and make the technology come to matter in a particular version of itself.

The statement that user representations and configurations can matter has a double meaning in STS. It refers both to how social categories like gender or age literally come to matter when technologies are shaped by, often stereotypical, user representations, and to how this particular version of the technology can matter in sociopolitical terms. For instance, Winner (1980) showed how bridges in Long Island were deliberately designed to be so low that busses, and therefore also the low-income citizens that depended on bus transportation, were kept out of exclusive areas. In this sense, materiality can be shaped in ways that matter to people in sociopolitical terms by perpetuating social inequality by sociomaterial means. It is in this sense that artifacts can be said to "have politics" (Winner, 1980). To the extent that many people become dependent on an artifact that perpetuates social inequality in a particular way, this material exercise of power can have far-reaching effects (Pfaffenberger, 1992). Feminist strands of research in STS have drawn on this notion to show how technologies and other artifacts perpetuate sexist (Berg and Lie, 1995; Rommes et al., 1999) and ageist (Neven, 2010, 2015; Peine and Neven, 2011) values in society. Thus, to say that technology matters, means not only to say that social categories can come to matter in the sense that they are quite literally materialized, but also that the choice of user representations and the potential capacity for the materiality to structure society for large groups of people can matter in sociopolitical terms. 


\section{RELATIONAL APPROACHES TO THE STUDY OF DEMENTIA}

Relational approaches to the study of dementia have evolved out of a critique of what is commonly referred to as a biomedical understanding of dementia (Bartlett and O'Connor, 2007; Brittain et al., 2010). From a biomedical perspective, dementia is a disease that while it may manifest in different ways at different times, carries a number of foreseeable implications. For instance, the gradual but ultimately inevitable loss of cognitive abilities necessary to competently manage the task of making informed decisions (Feinberg and Whitlatch, 2001; Karlawish et al., 2002). The biomedical understanding has for a long time, been the traditional way of understanding dementia (Kitwood, 1997; Bartlett and O'Connor, 2007). There are however, other and more relational ways of understanding dementia that challenge the biomedical model. Bartlett and O'Connor (2007) nicely capture the contrast between a biomedical understanding of dementia and more relational approaches when they write

the field [of research on dementia] is changing [...]. Until only recently expressions such as 'the confused' (Meacher, 1972) and 'dementia sufferers' (Jacques, 1992; Cheston and Bender, 1999) were commonly used. Now people with dementia are more likely to be referred to as 'people with dementia' [...]. A result of this shift is that gradually, research has begun to emerge aimed at capturing the perspectives of persons with dementia (see for example Braudy-Harris (2002); Wilkinson (2002)). This body of research now clearly documents that persons with dementia are often quite aware of their situation (Clare, 2002), and can contribute important and unique insights about their experiences and needs (Bender and Cheston, 1997; Braudy-Harris, 2002; Phinney and Chesla, 2003; Beard, 2004; Clare et al., 2005; Hirschman et al., 2005; Whitlatch et al., 2005).

What Bartlett and O'Connor (2007) are getting at here, is how more relational approaches to the study of dementia challenge the notion that dementia is a purely biomedical phenomenon. In difference to the biomedical approach that by default posits that people with dementia are less competent, relational approaches to dementia are characterized by an understanding of people with dementia as differently competent.

Bartlett and O'Connor (2007) describes how two main relational approaches to dementia have developed over time. These two approaches draw on different concepts, each of which can be used as "lenses," together or on their own, to highlight different aspects of interactions between people with dementia and their social surroundings. Initially developed by Kitwood (1997) the personhood concept has emerged as the so far most influential concept in relational approaches to dementia (Brooker, 2004; Woods, 2001) and has effectively displaced the notion that the biomedical approach to dementia is the only viable way of understanding dementia (O'Connor et al., 2006). In contrast, to the biomedical approach that assumes a trajectory of irrevocable decline, the personhood lens is characterized by the view that social interactions with others and others' perceptions of the self are equally important as neuropathological factors (O'Connor et al., 2006; Bartlett and O'Connor, 2007). Personhood has been used as a lens to analytically focus how biomedical understandings of dementia perpetuate the social stigma and discrimination associated with dementia, and its introduction has meant a shift where the importance of hearing the perspectives of people with dementia has become recognized (Bartlett and O'Connor, 2007). As a result, we now know that people with dementia are often aware of their situation, as well as of what they want and need (Bender and Cheston, 1997; Braudy-Harris, 2002; Clare, 2002; Phinney and Chesla, 2003; Beard, 2004; Clare et al., 2005; Hirschman et al., 2005; Whitlatch et al., 2005; Bartlett and O'Connor, 2007).

As Bartlett and O'Connor (2007) point out the personhood concept continues to be important, its use is limited because it does not provide a framework for the exploration of the possibility that care is sometimes constitutive of power and control (Fox, 1995). Personhood is an apolitical concept that is primarily concerned with psychosocial matters. For instance, quality of life is treated as a matter of experiencing well-being (Brock, 1993; Rudman, 1997) as opposed to a matter of exercising influence. As such, personhood does not provide an appropriate lens for the study of dementia care in terms of power and politics (Bartlett and O'Connor, 2007).

By contrast, the other main relational approach to dementia draws on a Foucauldian understanding of power (Foucault, 1967, 1980) and the notion of citizenship, precisely in order to describe social interactions between people with dementia and their social environments as sociopolitical power struggles (Bond, 1992; Harding and Palfry, 1997; Lyman, 1998; Gilleard and Higgs, 2001).

As Bartlett and O'Connor (2007) point out to dementia is characterized by the view that citizenship is not something that people simply have or do not have (Dreyfus and Rabinow, 1982), but rather, something that is accomplished in social interactions (Barnes et al., 2004). Thus, citizenship is defined as a practice (Shotter, 1993; Isin and Wood, 1999; Lister, 2003; Barnes et al., 2004) through which people with dementia relate to their social context (Prior et al., 1995). The notion that citizenship can be a practice challenges the more traditional notion of citizenship as set of rights and responsibilities that are bestowed on a person (Marshall, 1992) in formal processes of decision-making (Bartlett and O'Connor, 2007). From this perspective, power struggles and the retention or acquisition of citizenship are inevitably part of any social interaction between people with dementia and their social environment because these social interactions are the empirical sites where power and citizenship are accomplished. Drawing on the citizenship lens, research on decision-making processes in the context of care have shown that people with dementia and their carers often disagree in relation to risk. Carers are often prone to see risk as the management of physical risk, while older adults with dementia are often more concerned with risk in relation to their personal and social identities (Ballinger and Payne, 2002; Robinson et al., 2007; Hughes, 2008). Recently, studies of citizenship have also started to acknowledge that materialities also shape the experience of aging, with or without dementia (Joyce 
and Mamo, 2006) and that materialities are actors to be accounted for in the study of power-struggles between people with dementia and their social contexts (Brittain et al., 2010).

\section{METHOD}

The empirical material analyzed here was gathered through ethnographical fieldwork conducted during visits in 4 different showrooms in two urban and two rural areas of Norway in 2015. This study singles out one of these visits where I participated in an educational demonstration held for 25 nursing students by two educators. This type of demonstration or "demo" is part of a collaboration between the showroom and the university. The demo is given in the form of a lecture that includes demonstration of a variety of gerontechnologies. This lecture is part of a mandatory course in the university's master and bachelor programs in nursing and ergotherapy and is normally closed for members of the public. My own participation was the result of an invitation extended to me by the two educators, "Eva" and "Noora" during a meeting where I explained that I was interested in studying how they taught students about gerontechnologies for older adults with dementia. The ethical considerations of this study were reviewed and approved by the Norwegian Social Science Data Services (NSD). Written and verbal information about the study was distributed to all participants. Verbal informed consent to my presence as well as to being audio recorded and quoted for the purposes of research was obtained from all research participants. This consent procedure is in accordance with Norwegian law as well as the general ethical guidelines issued by NSD and the individual instructions provided to me by NSD as the start of this study. ${ }^{1}$ The audio recordings were transcribed word for word by a research assistant and translated from Norwegian to English by myself. Translations privilege clarity of meaning over verbatim. All names are fictional and all information concerning the care professionals professional titles and training, as well as the name and location of the showroom and the affiliated university are withheld to ensure anonymity. Pictures of the gerontechnologies that were taken during the lecture have been included to provide clarity for readers. These pictures were deliberately chosen because they do not compromise the integrity of the anonymization process.

In analyzing how the educators teach the nursing students I paid particular attention to how Eva and Noora taught the nursing students to mediate (Schot and De la Bruheze, 2003) the gerontechnologies demonstrated during the lecture by constructing user representations (Akrich, 1995) through descriptions of how older adults with dementia are prone to act toward technology. I also paid particular attention to how they used these user representations to teach the nursing students how they can configure this behavior and thus delimit the problems it can cause by shaping the technology in a way. These statements

${ }^{1}$ More information about Norwegian law and NSD's ethical guidelines in relation to consent procedures can be found here http://www.nsd.uib.no/personvernombud/ en/help/information_consent/ were not treated as fact or fiction, but as Noora's and Eva's verbalized meaning-making of the understandings that they using to shape the nurses strategies of action (Swidler, 1986, 2006) in their future roles as professionally active nurses who will use gerontechnologies to care for older adults with dementia who are aging at home. The analytical procedure drew on social constructionist grounded theory (Bryant and Charmaz, 2010; Charmaz, 2014). In vivo coded segments of the transcriptions were sorted into grounded categories through abductive inferencing (Reichertz, 2007), that informed subsequent theoretical coding (Bryant and Charmaz, 2010; Charmaz, 2014). Through this analysis, I identified three user representations (Akrich, 1995) which were described as typical behavior for older adults who are aging at home, two ways that nursing students are taught to strategically configure this behavior by material means and one rationale that enabled these configurations to be perceived as care as opposed to anything else. The three user representations were: cognitive inability to purposively use technology; recalcitrant behavior and attentiveness to the appearance of new items. The two ways of configuring this behavior was selection and placement of gerontechnologies and the rationale was a biomedical understanding of dementia. Thereafter I used the concept of personhood and the concept of citizenship as analytical lenses to interpret these results. This analysis enabled me to identify these user representations and configurations, and the rationale they are based on as sociomaterial means by which care professionals can mediate (Schot and De la Bruheze, 2003) gerontechnologies in ways that disempower older adults that are aging at home. On the basis of these combined results, I argue that care professionals can act as intermediaries (Pinch, 2003), and that their practices of shaping gerontechnology, for instance through placement and selection, can be understood as empirical sites where care professionals can exercise power over older adults with dementia who are aging at home, by sociomaterial means. I conclude that there is a continued need for studies of gerontechnologies that stage analytical dialogs between STS theory and understandings from other fields with longer traditions of studying processes of aging, to further elucidate how gerontechnologies are shaping and being shaped in ways that can matter to older adults and the experience of aging.

While the claims of this study are limited to the sample described, it should be noted that to the extent that many older adults with dementia who are aging at home become dependent on nurses who have been trained to mediate (Schot and De la Bruheze, 2003) gerontechnologies in this manner, these configurations may have far-reaching sociopolitical implications.

The following section describes the results of my analysis. It is structured as follows: I first identify inability to purposively use technology, recalcitrance and attentiveness as three problematic behaviors that are described as typical for older adults with dementia who are aging at home, and selection and placement of gerontechnologies as two ways in which the nursing students are taught to delimit this behavior by material means. Thereafter I show how selection and placement of gerontechnologies are means by which care professionals shape gerontechnologies in ways that can disempower older adults who are aging at home. 


\section{HOW NURSES ARE TAUGHT TO USE SELECTION AS A MEANS OF CONFIGURING DEMENTIA?}

In describing to the students what type of gerontechnology that older adults with dementia need in general terms, Noora distinguished between passive and active gerontechnologies

I differentiate between passive and active technology and when I say active technology, I refer to devices where the user needs to be active. Those are suitable in the early stages of dementia. Passive technology on the other hand, does not require an active user, it is just there to provide safety. For instance, by signaling if the user falls. Those technologies are more passive so they are suitable in later stages of dementia. So, this is about knowing what type of technology that fits with different stages of dementia.

In this quote, Noora is constructing two user representations of older adults with dementia who are aging at home. Users who are able to use technology in a purposeful manner, which she describes as the "early stages of dementia," and users where the individual is unable to use technology in a purposeful manner which she describes as "later stages of dementia." She also connects these user representations by identifying them as suitable users for two distinctly different types of gerontechnologies. She first identifies semi-automated gerontechnologies that she describes as "active technologies" where the individual with dementia is involved in the use of the device as suitable for older adults in early stages of dementia. She contrasts the description of semi-automated gerontechnologies against a description of fully automated gerontechnologies that she describes as "passive" gerontechnologies that "only produce safety" and describes them as suitable for older adults in the later stages of dementia.

In making these user representations and attaching them to the different types of gerontechnologies, Noora is teaching the students to configure older adults with dementia and bring dementia to matter through selections of gerontechnologies. If care professionals are selecting different types of gerontechnologies for different people and basing the selection on their assessment of the older adults "level" of dementia, as opposed to any other criteria, dementia is brought to matter through selective practices that materialize a particular type of gerontechnologies in the homes of older adults with dementia. As I will show in the following section, this configuration is not without its potential sociopolitical consequences.

\section{SELECTION AS CARE AND AS SOCIAL INEQUALITY}

To understand the sociopolitical potential of this configuration it is important to consider how Noora is able to accomplish a link between caring for older adults with dementia who are aging at home, and limiting the selection of gerontechnologies to fully automated devices that only produce safety.
This requires a different reading of Noora's quote. Specifically, a reading that on one hand focuses on how Noora is interpreting the situation from the position of a person with a deep understanding of the technologies she is about to demonstrate, and on the other hand considers the social capacity for materiality to shape the interpretations people attach to them.

Note for example, how Noora's description not only illustrates what the students should do when they become care professionals. It also illustrates her understanding that there are two types of gerontechnologies to choose from. Fully automated technologies that she describes as "passive technologies" that are only there to provide safety, and "active technologies" where the range of functions is not limited to the capacity to produce safety, but where the technology itself requires that the person using the technology does so actively.

Technologies intended for use by the general population often require very high levels of cognitive abilities, an implication of what has been described as our contemporary hyper cognitive society (Post, 2000). Early STS studies of technology design processes often described designers user representations as a result of the "I-method" (Akrich, 1992), meaning that the designer imagined user's needs and desires as similar to their own. Approximately a decade later, the routine inclusion of older adults that act as test subject in the development phase of gerontechnology production is described as a "sine qua non" (Sixsmith, 2013; Peine et al., 2015). This design strategy is employed precisely to avoid situations where the design of gerontechnologies configures the user as something else than an older adult (Neven, 2010). However, even though there has been progress, contemporary design processes for gerontechnologies often exclude people with dementia (Orpwood et al., 2010). Even in cases when the gerontechnology under development specifically targets this user group. For instance, Neven (2011) describes a case where the technology producer screened potential test persons for early signs of dementia because they believed people with dementia lacked the skill necessary for participation in the test process.

With this in mind, Noora's distinction between active and passive technologies can be understood as a verbalized description of her interpretation of how semi-automated and fully automated technologies configure users differently, leaving care professionals in the disempowered position of having with little to no choice but to match care recipients with the "right" type. From this perspective, the delimitation of the selection of gerontechnologies for older adults with dementia who are aging at home to fully automated gerontechnologies that only produce safety can be understood as the more caring alternative to selecting gerontechnologies that such older adults cannot operate.

However, if older adults with clearly pronounced dementia are only provided with gerontechnologies that produce safety it means that they are being exempted from gerontechnologies that produce the other benefits mentioned in the definition of welfare technologies. This definition clearly specifies that welfare technologies should provide increased safety, social inclusion, mobility and physical and cultural activity, as well as increase the individuals' possibility to manage everyday life on their own despite decreased psychological or physical capacities (NOU, 2012, p. 99). Thus, this configuration of dementia not only has the capacity 
to bring dementia to matter in the form of material differences between gerontechnologies offered to adults with more or less clear signs of dementia. It also has the capacity to matter to older adults with clear signs of dementia who are aging at home by producing social inequality in the form of a delimitation of their access to gerontechnologies that produce other benefits that safety. As such, the selection of gerontechnologies is a material mode through which care professionals can configure dementia and make dementia matter in ways that may produce social inequality for the recipients of their care.

As I will argue shortly, this highlights precisely why the act of selecting gerontechnologies for older adults with dementia is an important empirical site for the study of power struggles between care professionals and older adults with dementia who are aging at home. However, before doing so I will first describe how placement configures dementia and brings dementia to matter in ways that can have sociopolitical implications for the older adults with dementia who may have to depend on care professionals decisions.

\section{HOW NURSES ARE TAUGHT TO USE PLACEMENT AS A MATERIAL MODE OF CONFIGURING DEMENTIA}

When teaching the students about gerontechnologies that are suitable for all older adults with dementia who are aging at home, Eva and Noora showcased a large variety of ambient assisted living technologies (AAL's). AAL's are a form of information and communication technologies (ICT's) that allow caregivers to gain insight into the goings on in the older adults home from afar in the case of an incident that triggers the technology. Such devices can depend on cameras, but sensors are more common in Norway due to restrictive legislation and Eva and Noora only demonstrated AAL's with sensors to the nursing students. When teaching the students about AAL's, Eva and Noora showcased large, flat pressure sensors, meaning sensors that are able to register the presence or absence of pressure, that can be placed in beds, on the floor, inside doormats and in chairs, as well as smaller pressure sensors and motion sensors that can be fixed to various surfaces (see Figures 1-4 for pictures of some of these sensors). All of the sensors are ICT's with the capacity to alert care professionals should they be triggered, either by sending a text message to a designated mobile phone or a signal to an alarm central.

When teaching the students about AAL's Eva described AAL's as suitable for all older adults with dementia. However, she also described recalcitrant behavior toward AAL's as typical for people with dementia and constitutive of pitfalls that care professionals must anticipate.

We have to be able to anticipate these pitfalls because [older adults with dementia who are aging at home] can become pretty creative when they start to think that these devices are annoying.

In describing recalcitrant behavior of older adults with dementia as "pitfalls," Eva is referring to the capacity for older

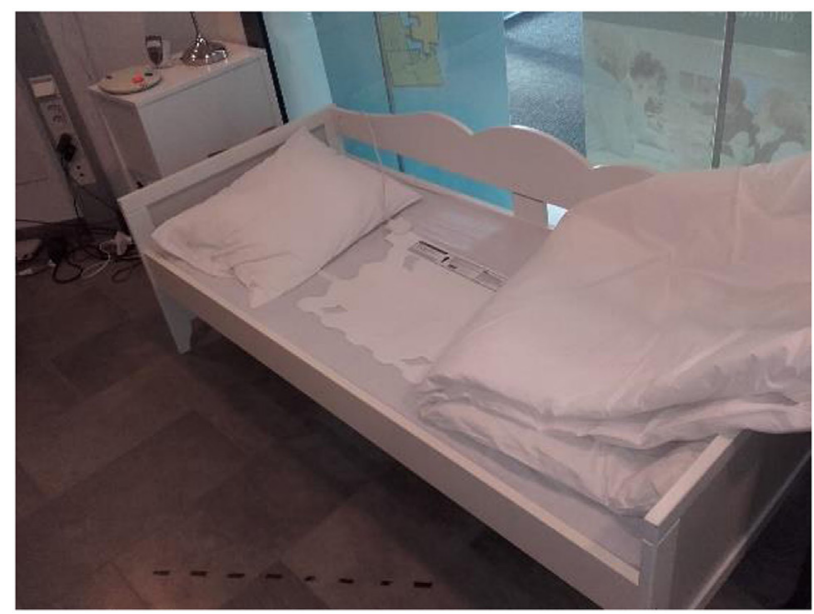

FIGURE 1 | Bed equipped with a visible flat pressure sensitive sensor.

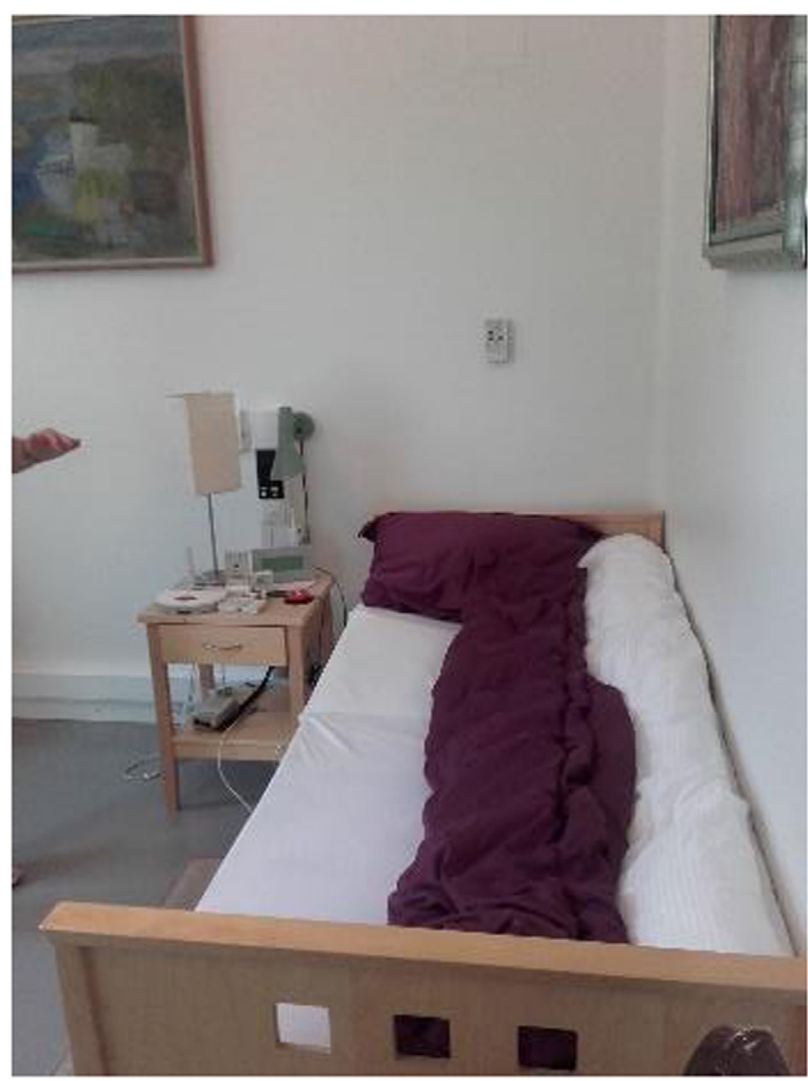

FIGURE 2 | Bed where the flat pressure sensitive sensor has been concealed under the white bedsheet.

adults with dementia to disrupt the functionality of AAL as a general tendency for people with dementia and constructing it as a problem that care professionals must solve.

In demonstrating an AAL in the form of a flat sensor that is meant to be placed in beds (see Figure 1) Noora made a similar 


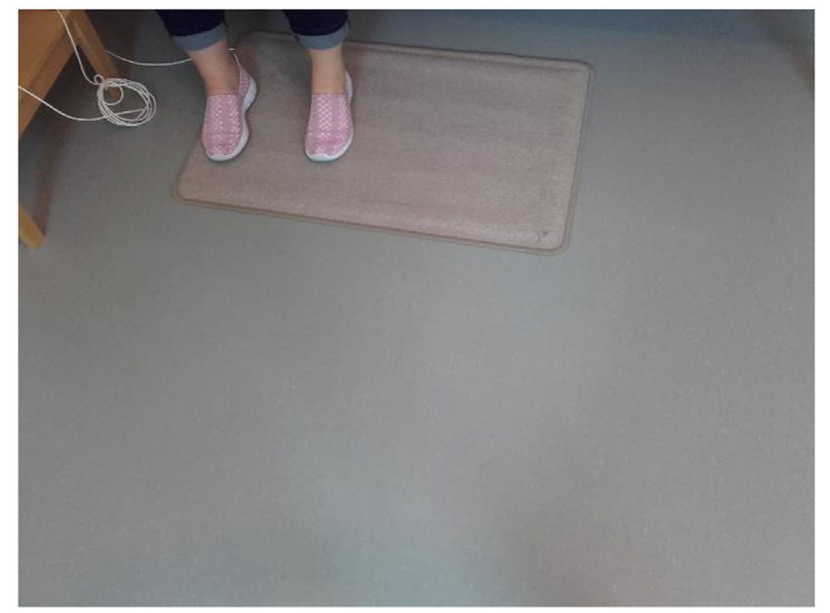

FIGURE 3 | Doormat with integrated sensor.

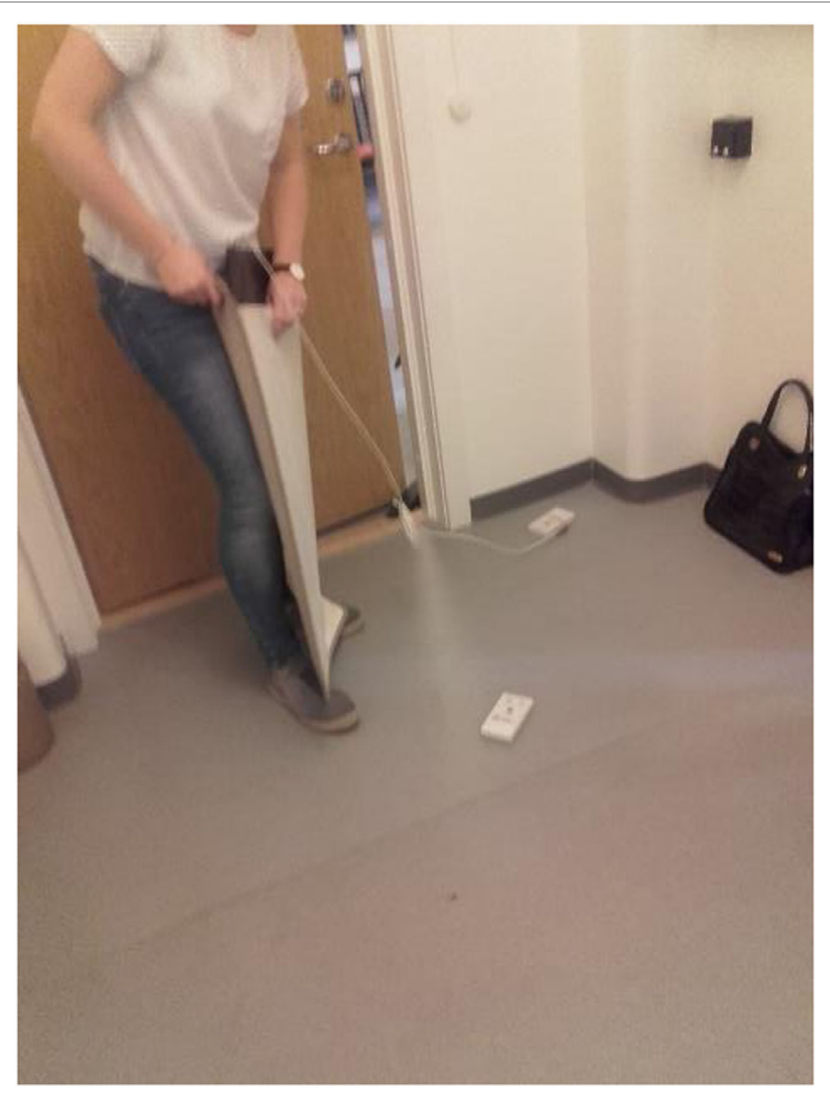

FIGURE 4 | Doormat with removable pressure sensitive sensor.

description when she referred to a scene in an educational video produced by another municipality and distributed via YouTube

I have to ask, have you seen the movie "Margot challenges the welfare technology? You should google it if you have not seen it yet. Anyway, it has a funny point to it. There is this lady that has a bedsensor like the one I will show you, and the alarm clock goes off in the middle of the night, and at first she is confused but then she remembers - it's time to watch the superball finals! And she goes up to watch tv, and then alarms start to sound and Margot is healthy and has moderate dementia so she is annoyed that the technology has told the care professionals that she is out of bed. So she gets a vacuum cleaner and some books and a potted plant and puts them on the pressure sensivtive sensor so that it will believe that she is still in bed. So that is funny. But it also tells us something about how [care professionals] need to think when we are placing the technology so that we delimit the risk that people can tamper with the technology."

Ending this story, Noora pulled back the covers of a bed placed in the showroom and lifted the bedsheet to show how a flat sensor can be hidden under the bedsheet to disinvite tampering.

Describing this scene, Noora constructs it in a particular way. Dementia is never mentioned in this movie. However, in Noora's description the lead character Margot has "moderate dementia," by which she means dementia that is pronounced but not always manifest. Thereafter, Noora describes Margot's attempt to fool the pressure sensitive sensor by piling things on it as "tampering" a behavior she describes as caused by annoyance with the technology. Together, these descriptions link Margot's behavior to dementia and simultaneously frames that behavior as recalcitrant and irrational, as well as potentially dangerous. Finally, Noora describes this story as an example that shows how important it is that care professionals carefully consider the placement of sensors. She then describes the proper placement of sensors as a placement that disallows "tampering" and lifts the bedsheet to reveal the concealed bedsensor.

In doing so, Noora defines the significance of her story to the students, not as a description of a potentially funny move, but a real example of recalcitrant behavior that is typical for people with dementia. Thereafter she ties this description to demonstration of an invisible sensor and refers to it as an example of a placement that can counter such behavior. In other words, she uses her description of Margot to construct a user representation of older adults with dementia who are aging at home as typically recalcitrant and then shows how care professionals can deliberately use the placement of sensors as a means of configuring recalcitrant behavior to solicit compliance.

The placement of sensors was also described as an important means by which care professionals can configure older adults with dementia to solicit compliance in relation to other AAL's when Eva demonstrated a type of AAL that depends on a sensor that is placed on the floor. This particular sensor is meant to signal to care professionals that someone has left their apartment or house and needs to be found before there is an incident. When Eva demonstrated these AAL's she showcased a doormat placed in front of the entrance to the showroom and explained that while these AAL's are typically integrated into doormats, the appearance of a new doormat and visible cables in the home of an older adult with dementia triggers tampering. 
Eva: Here in the hallway we have a few different ways of detecting that someone has left their house. So if one of you could please exit through the door we can see what happens [beeping sound from mobile phone]. Now this doormat sensed that [the student] stepped on it, so now it sent me a text message that informs me that someone has left their house. So the doormat is connected to the transmitter over there. I would not have set it up like this in the home of an actual [older adult with dementia] but what I want to show you is that this transmitter also works with the pressure sensitive sensor in the bed.

In demonstrating the doormat Eva first describes it as one of many technologies that care professionals can use to discover if an older adults with dementia has left their home. She then proceeds to describe how the doormat sends a text to a mobile phone when it registers that someone steps on it and explains that the signal is not sent directly from the doormat, but from a small transmitter connected to the sensor in the doormat by a cable and hung on a radiator. She also refers to this placement of the transmitter in the showroom as a misrepresentative example of how transmitters should be placed in the home of an older adult with dementia. At this point, I asked why she thought that the transmitter should not be placed in this way in the actual home of and older adult with dementia.

J: Sorry, you said that you would not have set it up like this in the home of an actual [older adult with dementia], why not?

E: Good that you ask. When I said that I referred to how I would not leave the cables out in the open like that. If there was a carpet or a chest of drawers there I would have hidden the cables. Because, as we talked about before, if an [older adult with dementia] sees that something has changed they start to mess with it. So that is what I mean when I say that I would not set it up like this on the home of an actual [older adults with dementia]. And this doormat is especially good because it is possible to remove this one, this black sensor, and then you can place it under the usual doormat so that it looks like nothing has changed.

When Eva answered my question, she described older adults with dementia as attentive and prone to "mess with" new objects in their home, and the visibility of new artifacts as problematic because it can spur this tendency. Eva uses this description to illustrate what a "good" placement looks like and describes this placement in terms of concealment. The sensor, the cables and the transmitter must be hidden to reduce the risk that the device is "messed with." Eva is also providing examples of how a concealed placement can be accomplished pragmatically when she explains that cables can be hidden behind furniture like chairs and chests of drawers. Finally, she explains that a particular type of doormat is especially suited to such hiding because it allows for removal of the sensor which can then be placed under the doormat or rug already present in the putative users home, something which will help in the accomplishment of an illusion of no-change (see Figure 3 for a picture of this doormat).

Eva's use of the term "mess with" is important in this context because it frames older adults interactions with the technology as problematic. Somebody who is "messing with" technology is not simply adjusting it to their liking, but disrupting it. By using this term to conceptualize the behavior of older adults with dementia toward visible parts of the technology Eva accomplishes a rationale for hiding the technology. A second observation is that she initiates this explanation by defining the unconcealed placement of the technology as unsuitable in the home of a care recipient. Thus, she is referring back to her previous description of what the technology does to identify the type of care recipient she is talking about as a care recipients with dementia who may wander off in the night and need to be found by care professionals. Together, these three statements thus act together to coconstruct the notion that the technology must always be hidden in the home of all service recipients with dementia where it is installed because their interaction with the technology is disruptive due to incompetence.

In making this explanation, Eva is constructing a user representation (Akrich, 1995) of older adults with dementia who are aging at home as a problem to the technology. They are people who cannot be trusted with the technology in their homes. She then draws on this user representation to construct the strategic concealment of technology as a way that the students can and should configure (Woolgar, 1990) older adults with dementia while simultaneously delimiting their possibility to notice and "fiddle" with the technology.

The strategical value of selection is also illustrated by Eva's description. By describing the doormat with a removable sensor as particularly suited to the accomplishment of the ideal of a concealed placement, Eva is drawing on the user representation (Akrich, 1995) she has constructed to single out a specific device as particularly valuable in configuration (Woolgar, 1990) of older adults with dementia. In doing so, she is simultaneously constructing the selection of this device as a means by which care professionals can delimit the possibility for older adults to "mess with" the technology. In this sense, selection is part of the accomplishment of a visual illusion meant to configure older adults with dementia by delimiting not only access to, but also knowledge of the presence of technology in their home.

\section{PLACEMENT AS CARE AND AS A MEANS OF SUBVERSIVELY SOLICITING COMPLIANCE}

In teaching the students about how they should configure older adults with dementia who are aging at home by placing AAL's such as bed sensors and doormats where they are less visible when they become care professionals, Eva and Noora are describing the concealed placement of the sensors and cables as a way of ensuring the functionality of the technology. In other words, they are illustrating how the students can act to ensure that the technology will function as intended. Meaning that it will be able 
to alert care professionals in the case of an incident where an older adult with dementia leaves their bed or home. At least as far as such insurances are possible by material means.

Research that draws on biomedical understandings of dementia has often described dementia in terms of a flawed ability to make well-informed choices (Feinberg and Whitlatch, 2001; Karlawish et al., 2002). Thus, from a biomedical perspective, Noora and Eva's descriptions of how older adults with dementia are prone to, intentionally or unintentionally, disable sensors meant to keep them safe can be understood as illustrative of an understanding of dementia as manifest in confused behavior that is constitutive of risk to the individual's safety. Inferencing from this understanding, it is possible to see how Noora's and Eva's are able to understand their descriptions of how the students should use the concealed placement of AAL's as a strategic means of caring for older adults with dementia who are aging at home by hindering them from intentionally or unintentionally disabling the technology.

However, other interpretations are possible too. Consider for instance Noora's example of the recalcitrant tendency to intentionally disable visible bed sensors that she describes as typical for older adults with dementia. In describing this behavior, she is referring to this tendency as caused by an unwillingness to allow the technology to alert care professionals when the individual leaves the bed. In other words, hiding the technology can also be understood as a method of soliciting compliance from older adults with dementia who do not want this technology.

In the case of the doormat, the method of using placement and selection as means of hiding the technology is meant to delimit the possibility for older adults to "mess with" the technology by delimiting their possibility of knowing that the technology has been placed in their hallway. Thus in this case, the selection and placement of gerontechnologies is described as a means of disempowering older adults with dementia by rendering them oblivious of the technology's presence.

\section{HOW SELECTION AND PLACEMENT CAN BE OCCASIONED BY A BIOMEDICAL UNDERSTANDING OF DEMENTIA?}

So far, I have identified the selection and placement of gerontechnologies as two material means by which nurses are taught to configure older adults with dementia who are aging at home. I have also showed that while these selections and placements can be understood as caring practices, they can also be constitutive of social inequality and used by care professionals to subversively solicit compliance from older adults with dementia who are trying to reject the technology. In this section, I will show how this notion of caring relies on a biomedical understanding of dementia and I will show how care professionals practices of selecting and placing gerontechnologies can be understood as important empirical sites for the study of power struggles between care professionals and older adults with dementia.

If nurses limit their selection of gerontechnologies to fully automated devices that only produce safety, they do on the one hand eliminate the risk that the older adults will be paired with a technology that they cannot operate. However, social inequality is also being produced because it delimits the possibilities for those care recipients to receive other technologies that are capable of producing other effects. Similarly, if care professionals hide sensors and cables they do on the one hand solicit compliance from older adults but on the other hand they are doing so in order to eliminate the risk that the older adult intentionally or unintentionally disassembles the technology. Thus, these situations can in themselves be understood as descriptions of caring practices that carry the downside of also being constitutive of social inequality and disempowerment, or, stories where safely aging at home for an adult with dementia comes at a price. So how are the educators able to understand this as a caring practice?

When Noora and Eva describe how the nursing students should select and place gerontechnologies in particular ways when the care recipient is an older adult with dementia who is aging at home, they do so by illustrating these selections and placements as care. This verbal accomplishment of selections and placements of gerontechnologies as care, depends on the illustration of nurses practices of selecting and placing gerontechnologies in particular ways as a means of countering risks. Specifically, that older adults will be unable to use technologies as well as intentionally or unintentionally disable sensors. In other words, this description of care relies on the notion that older adults with dementia who are aging at home lack the cognitive capacity to competently make their own decisions and adequately assess risk scenarios. This view is relatively common, particularly amongst care professionals (Ballinger and Payne, 2002; Robinson et al., 2007; Hughes, 2008).

With this in mind, it is possible to revisit the analysis and reconsider the notion that care professionals should select and place gerontechnologies in terms of privileges being awarded to care professionals at the cost of including the older adults with dementia in the decision making process. In the analysis, I showed how a delimitation in the selection of gerontechnologies for older adults with dementia who are aging at home is constitutive of social inequality when it means that these older adults are only supplied with gerontechnologies that produce safety. As opposed to gerontechnologies that are capable of producing other benefits such as "social inclusion, mobility and physical and cultural activity" (NOU, 2012, p. 99). I also showed that this delimitation in care professional's choices can be understood as a caring practice when understood as a way of delimiting the risk that older adults with dementia are supplied with technologies that they cannot operate. However, this notion of caring is reliant on the idea that older adults with dementia who are aging at home are fundamentally incapable of choosing for themselves or even participating in the decisionmaking process. This notion is characteristic for a biomedical understanding of dementia.

Thus, while the educators are configuring gerontechnologies, the educators are simultaneously being configured themselves by a biomedical understanding of dementia that shapes how they understand the possibilities for older adults with dementia to interact with gerontechnology. 


\section{MEDIATION AS AN EMPIRICAL SITE WHERE CARE PROFESSIONALS CAN DISTRIBUTE POWER BETWEEN GERONTECHNOLOGIES AND OLDER ADULTS}

As I have shown, the act of selecting gerontechnologies is no trivial matter and can produce social inequality for older adults with dementia who are aging at home. As such, decision-making processes related to the selection of technologies are sociopolitical and can be understood as practices where citizenship is enacted. To exempt older adults with dementia who are aging at home from decision-making processes that concerns them means to deny them the possibility of exercising citizenship by exerting influence in that decision-making processes. In the above description of the citizenship literature, I show how power struggles and the retention or acquisition of citizenship are part of any social interaction between people with dementia and their social environment because these social interactions are the empirical sites where power and citizenship is accomplished. Thus, from a citizenship perspective, the production of social inequality is not limited to the choices that care professionals make, but inherent in the selection process itself when older adults with dementia are being denied the possibility of exercising citizenship by influencing the selection. From this perspective, power struggles and the retention or acquisition of citizenship are also inevitably part of any selection process related to types of gerontechnology, because these social selection processes are the empirical sites where power and citizenship are accomplished. Ballinger and Payne (2002), Hughes (2008) and Robinson et al. (2007) have shown that carers are often prone to see risk as the management of physical risk, while older adults with dementia are often more concerned with risk in relation to their personal and social identities. Here I showed that the delimitation of gerontechnologies to fully automated technologies that only produce safety is described as the correct way of caring for older adults who are aging at home because it delimits the risk that older adults will have technologies that they will not be able to operate, but perhaps those older adults have other preferences?

Similarly, it is possible to draw on the notion of citizenship to revisit and re-evaluate the idea that care professionals should delimit the risk that older adults with dementia who are aging at home disable their AAL's through the strategic use of concealed placement. From this perspective, the strategic use of concealed placement as a means of delimiting the care recipients' knowledge of the presence of AAL's in their home, or to solicit compliance from "recalcitrant" older adults who intentionally try to disable bed sensors is possible to understand as delimiting of the care recipients possibilities to enact citizenship by rejecting the technology. For instance, Paterson and Hughes (1999) (p. 604) describe how the ways that people with dementia alter their physical surroundings can be understood as a "quest for citizenship." As such, the concealed placement of gerontechnologies can be understood as a way that the care recipient is being disempowered in relation to their possibilities of enacting citizenship by rejecting the technology.
In this sense, the capacity for care professionals to mediate gerontechnologies and configure older adults, for instance through selection and placement, can be understood as a capacity to distribute power in the relationship between gerontechnologies and the older adults that become the users of those technologies. From this follows that care professionals practices of mediating gerontechnologies and configuring older adults is an important empirical site for the study of how gerontechnologies shape the experience of aging.

\section{A CONTINUED NEED FOR DIALOG}

While I do not claim to provide an exhaustive account of how care professionals can act as intermediaries (Pinch, 2003) or of how they can mediate (Schot and De la Bruheze, 2003) gerontechnologies, I have shown that nursing students are taught to mediate (Schot and De la Bruheze, 2003) gerontechnologies as part of their training. I have shown how such mediation can be accomplished through the selection and placement of gerontechnologies, and that selection and placement can configure older adults with dementia who are aging at home. I have also shown how this configuration brings dementia to matter in ways that can produce social inequality and loss of citizenship for older adults with dementia who are aging at home, and I have shown how the understanding that this configuration is constitutive of care as opposed to anything else is occasioned by a biomedical understanding of dementia. On the basis of these results, I have argued that care professionals practices of shaping gerontechnologies can be understood, and studied as empirical sites where power is being distributed in relationships between gerontechnologies and the older adults that becomes the user.

The dialog between STS theories on intermediaries (Pinch, 2003), mediation (Schot and De la Bruheze, 2003), the sociopolitical capacity of materialities, and relational approaches to dementia (Bartlett and O'Connor, 2007; Brittain et al., 2010), that I have staged in this analysis offers a possibility for STS researchers to rethink how gerontechnologies shape the experience of aging.

While STS research has a long tradition of showing how materiality can matter in sociopolitical terms, STS research that has focused on gerontechnologies have so far only credited designers with the possibility of drawing on user representations to configure older adults by shaping the technology (see Joyce et al. (2017) for a comprehensive and recent overview of this research).

By contrast, this article has shown that care professionals can act as intermediaries and mediate gerontechnologies, and that their mediation of gerontechnologies can matter to older adults in sociopolitical terms. I have also shown that such mediation may be accomplished by mundane means like selecting and placing gerontechnologies in particular ways. STS has the tools to describe how older adults can be configured by sociomaterial means, as well as the tools to describe how sociomaterial configurations matter to older adult users. However, STS has arguably a very short history of engaging with the relationship between technologies and processes of aging (Östlund, 2004; Joyce and Mamo, 2006) and lacks a research tradition that describes the interplay between care professionals and older adults in terms of power and politics. By staging the analytical dialog between 
STS and relational approaches to dementia I have showed how concepts like personhood and citizenship can enrich the interpretation of how mediation and configuration can matter to older adults. From this I conclude that there is a continued need for empirical studies of gerontechnologies that stage analytical dialogs between STS theory and understandings from other fields with longer traditions of studying processes of aging, to further elucidate how gerontechnologies can matter to older adults and the experience of aging.

\section{ETHICS STATEMENT}

The ethical considerations of this study were reviewed and approved by the Norwegian Social Science Data Services (NSD). Written and verbal information about the study was distributed to all participants. Verbal informed consent to my presence as

\section{REFERENCES}

Akrich, M. (1992). "The De-scription of technical objects," in Shaping Technology/ Building Society Studies in Sociotechnical Change, eds W. E. Bijker and J. Law (Cambridge, MA: The MIT Press), 205-224.

Akrich, M. (1995). "User representations: practices, methods and sociology," in Managing Technology in Society: The Approach of Constructive Technology Assessment, eds A. Rip, T. J. Misa, and J. Schot (London: Pinter), 167-184.

Ballinger, C., and Payne, S. (2002). The construction of the risk of falling among and by older people. Ageing Soc. 22, 305-324. doi:10.1017/S0144686X02008620

Barnes, R., Auburn, T., and Lea, S. (2004). Citizenship in practice. Br. J. Soc. Psychol. 43, 187-206. doi:10.1348/0144666041501705

Bartlett, R., and O'Connor, D. (2007). From personhood to citizenship: broadening the lens for dementia practice and research. J. Aging Stud. 21, 107-118. doi:10.1016/j.jaging.2006.09.002

Beard, R. (2004). In theirvoices: identity preservation and experiences of Alzheimer's disease. J. Aging Stud. 18, 415-428. doi:10.1016/j.jaging.2004.06.005

Bender, M., and Cheston, R. (1997). Inhabitants of a Lost Kingdom; a model of the subjective experiences of dementia. Ageing Soc. 17, 513-532. doi:10.1017/ S0144686X97006570

Berg, A.-J., and Lie, M. (1995). Feminism and constructivism: do artifacts have gender? Sci. Technol. Hum. Values 20, 332-351. doi:10.1177/016224399502000304

Bond, J. (1992). The medicalisation of dementia. J. Aging Stud. 6, 397-403. doi:10.1016/0890-4065(92)90020-7

Braudy-Harris, P. (ed.) (2002). The Person with Alzheimer's Disease: Pathways to Understanding the Experience. Baltimore: The John Hopkins University Press.

Brittain, K., Corner, L., Robinson, L., and Bond, J. (2010). Ageing in place and technologies of place: the lived experience of people with dementia in changing social, physical and technological environments. Sociol. Health Illn. 32, 272-287. doi:10.1111/j.1467-9566.2009.01203.x

Broadbent, E., Stafford, R., and MacDonald, B. (2009). Acceptance of healthcare robots for the older population: review and future directions. Int. J. Soc. Robot. 4, 319-330. doi:10.1007/s12369-009-0030-6

Brock, D. (1993). Life and Death: Philosophical Essays in Biomedical Ethics. Cambridge: Cambridge University Press.

Brooker, D. (2004). What is person centered dementia care? Rev Clin Gerontol 13, 215-222.

Bryant, A., and Charmaz, K. (eds) (2010). The SAGE Handbook of Grounded Theory: Paperback Edition. SAGE. Available at: https://books.google.com/ books?id=OrgZjp9CoN8C\&pgis=1

Cagnin, C., Amanatidou, E., and Keenan, M. (2012). Orienting European innovation systems towards grand challenges and the roles that FTA can play. Sci. Public Policy 39, 140-152. doi:10.1093/scipol/scs014

Charmaz, K. (2014). Constructing Grounded Theory. Available at: http://www. google.no/books?hl=sv\&lr=\&id=v_GGAwAAQBAJ\&pgis $=1$

Charness, N., and Schaie, K. (eds) (2003). Impact of Technology on Successful Aging. New York: Springer Publishing Company.

Cheston, R., and Bender, M. (1999). Understanding Dementia: The Man with the Worried Eyes. London: Jessica Kingsley Publishers Ltd. well as to being audio recorded and quoted for the purposes of research was obtained from all research participants. This consent procedure is in accordance with Norwegian law as well as the general ethical guidelines issued by NSD and the individual instructions provided to the author by NSD at the start of this study.

\section{AUTHOR CONTRIBUTIONS}

All contents of this article and the research it builds on is the author's own work.

\section{FUNDING}

The funding for this research was provided by The Faculty of Humanities, Norwegian University of Science and Technology.

Clare, L. (2002). We'll fight as long as we can: coping with the onset of Alzheimer's disease. Ageing Ment. Health 6, 139-148. doi:10.1080/13607860220126826

Clare, L., Roth, I., and Pratt, R. (2005). Perceptions of change over time in early-stage Alzheimer's disease: implications for understanding awareness and coping style. Dementia 4, 487-521. doi:10.1177/1471301205058304

De Smedt, P., Borch, K., and Fuller, T. (2013). Future scenarios to inspire innovation. Technol. Forecast. Soc. Change 80, 432-443. doi:10.1016/j.techfore.2012. 10.006

Dreyfus, H. L., and Rabinow, P. (1982). Michel Foucault: Beyond Structuralism and Hermeneutics. Brighton: The Harves.

Feinberg, L. F., and Whitlatch, C. J. (2001). Are persons with cognitive impairment able to state consistent choices? Gerontologist 41, 374-382. doi:10.1093/ geront/41.3.374

Foucault, M. (1967). Madness and Civilisation: A History of Insanity in the Age of Reason. London: Tavistock.

Foucault, M. (1980). Power/Knowledge: Selected Interviews and Other Writings. London: Harvester.

Fox, N. (1995). Postmodern perspectives on care: the vigil and the gift. Crit. Soc. Policy 15, 107-125. doi:10.1177/026101839501504407

Gilleard, C., and Higgs, P. (2001). Cultures of Ageing: Self, Citizen and the Body. London: Pearson Education.

Graafmans, J., Taipale, V., and Charness, N. (eds) (1998). Gerontechnology - A Sustainable Investment in the Future. Amsterdam: IOS Press.

Gray, L. C., Bernabei, R., Berg, K., Finne-Soveri, H., Fries, B. E., Hirdes, J. P., et al. (2008). Standardizing assessment of elderly people in acute care: the interRAI acute care instrument. J. Am. Geriatr. Soc. 56, 536-541. doi:10.1111/j.1532-5415.2007.01590.x

Harding, N., and Palfry, N. (1997). The Social Construction of Dementia: Confused Professionals? London: Jessica Kingsley.

Helsedirektoratet. (2012). Velferdsteknologi. Fagrapport om Implementering av Velferdsteknologi i de Kommunale Helse- og Omsorgstjenestene 2013-2030. Oslo: Helsedirektoratet.

Hirschman, K. B., Joyce, C. M., James, B. D., Xie, S. X., and Karlawish, J. H. T. (2005). Do Alzheimer's disease patients want to participate in a treatment decision, and would their caregivers let them? Gerontologist 45, 381-388. doi:10.1093/geront/45.3.381

Hughes, R. (2008). Safer walking? Issues and ethics in the use of electronic surveillance of people with dementia. J.Assert. Technol. 2, 45-48. doi:10.1108/17549450200800007

Isin, E., and Wood, P. (1999). Citizenship and Identity. London: SAGE.

Jacques, A. (1992). Understanding Dementia, 2nd Edn. Edinburgh: Churchill Livingstone.

Joyce, K., and Loe, M. (2010). A sociological approach to ageing, technology and health. Sociol. Health Illn. 32, 171-180. doi:10.1111/j.1467-9566.2009.01219.x

Joyce, K., and Mamo, L. (2006). "Greying the Cyborg. New directions in feminist analyses of aging, science and technology," in Age Matters: Realigning Feminist Thinking (New York, London: Taylor \& Francis), 99-121.

Joyce, K., Peine, A., Neven, L., and Kohlbacher, F. (2017). "Aging: the socio-material constitution of later life," in The Handbook of Science and Technology Studies, 
4th Edn, eds U. Felt, R. Fouché, C. A. Miller, and L. Smith-Doerr (Cambridge, MA: MIT Press), 915-942.

Karlawish, J. H., Casarett, D., Propert, K. J., James, B. D., and Clark, C. M. (2002). Relationship between Alzheimer's disease severity and patient participation in decisions about their medical care. J. Geriatr. Psychiatry Neurol. 15, 68-72. doi:10.1177/089198870201500203

Kitwood, T. (1997). Dementia Reconsidered: The Person Comes First. Buckingham: Open University Press.

Lister, R. (2003). Citizenship: Feminist Perspectives. London: Macmillan Press Ltd.

Lyman, K. (1998). Living with Alzheimer's disease: the creation of meaning among persons with dementia. J. Clin. Ethics 9, 49-57.

Marres, N. (2013). Why political ontology must be experimentalized: on eco-show homes as devices of participation. Soc. Stud. Sci. 43, 417-443. doi:10.1177/0306312712475255

Marshall, T. H. (1992). "Citizenship and social class," in Citizenship and Social Class, 2nd Edn, eds T. Marshal and T. Bottomore (London: Pluto Press), 3-51.

Meacher, M. (1972). Taken for a Ride: Special Residential Homes for Confused Old People, a Study of Separatism in Social Policy. Bristol: Longman.

Mort, M., Roberts, C., and Callen, B. (2012). Ageing with telecare: care or coercion in austerity? Sociol. Health Illn. 35, 799-812. doi:10.1111/j.1467-9566.2012. 01530.x

Neven, L. (2010). "But obviously not for me": robots, laboratories and the defiant identity of elder test users. Sociol. Health Illn. 32, 335-347. doi:10.1111/ j.1467-9566.2009.01218.x

Neven, L. (2011). Representations of the Old and Ageing in the Design of the New and Emerging: Assessing the Design of Ambient Intelligence Technologies for Older People. Enschede: University of Twente.

Neven, L. (2015). By any means? Questioning the link between gerontechnological innovation and older people's wish to live at home. Technol. Forecast. Soc. Change 93, 32-43. doi:10.1016/j.techfore.2014.04.016

NOU 2011:22 Fra Bruker til Borger.pdf. (2011). Available at: http://www.regjeringen.no/Rpub/NOU/20012001/022/PDFA/NOU200120010022000DDDPDFA. pdf

NOU 2011:11. (2012). Innovation in the Care Services. Oslo: Norwegian Official Reports.

Nye, S. (2009). Resolving Messy Policy Problems: Handling Conflict in Environmental, Transport, Health and Ageing Policy. London: Earthscan.

O'Connor, D. L., Phinney, A., Smith, A., Small, J., Purves, P., Perry, J., et al. (2006). Dementia Care: Developing a Research Agenda for Broadening the Vision.

Orpwood, R., Chadd, J., Howcroft, D., Sixsmith, A., Torrington, J., Gibson, G., et al. (2010). Designing technology to improve quality of life for people with dementia: user-led approaches. Univ. Access Inf. Soc. 9, 249-259. doi:10.1007/ s10209-009-0172-1

Östlund, B. (2004). Social science research on technology and the elderly - does it exist? Sci. Stud. 17, 44-62.

Oudshoorn, N., and Pinch, T. (2003). "Introduction: how users and non-users matter," in How Users Matter: The Co-Construction of Users and Technology, eds N. Oudshoorn and T. Pinch (Cambridge: MIT Press), 1-25.

Paterson, K., andHughes, B. (1999).Disabilitystudies and phenomenology:thecarnal politics of everyday life. Disabil. Soc. 14, 597-610. doi:10.1080/09687599925966

Peine, A., Faulkner, A., Jaeger, B., and Moors, E. (2015). Science, technology and the "grand challenge" of ageing - understanding the socio-material constitution of later life. Technol. Forecast. Soc. Change 93, 1-9. doi:10.1016/j. techfore.2014.11.010

Peine, A., and Herrmann, A. (2012). The sources of use knowledge: towards integrating the dynamics of technology use and design in the articulation of societal challenges. Technol. Forecast. Soc. Change 79, 1495-1512. doi:10.1016/j. techfore.2012.04.014

Peine, A., and Neven, L. (2011). Social-structural lag revisited. Gerontechnology 10, 125-135. doi:10.4017/gt.2011.10.3.002.00

Pekkarinen, L., Sinervo, T., Elovainio, M., Noro, A., Finne-Soveri, H., and Leskinen, E. (2006). Resident care needs and work stressors in special care units versus non-specialized longterm care units. Res. Nurs. Health 29, 465-476. doi:10.1002/ nur.20157

Pekkarinen, L., Sinervo, T., Perälä, M.-L., and Elovainio, M. (2004). Work stressors and the quality of life in long-term care units. Gerontologist 44, 633-643. doi:10.1093/geront/44.5.633

Pfaffenberger, B. (1992). Technological dramas. Sci. Technol. Hum. Values 17, 282-312. doi:10.1177/016224399201700302
Phinney, A., and Chesla, C. (2003). The lived body in dementia. J. Aging Stud. 17, 283-299. doi:10.1016/S0890-4065(03)00029-X

Pinch, T. (2003). "Giving birth to new users: how the Minimoog was sold to rock and roll," in How Users Matter. The Co-Construction of Users and Technology, eds N. Oudshoorn and T. Pinch (Cambridge: MIT Press), 247-271.

Post, S. (2000). "The concept of Alzheimer disease in a hypercognitive society," in Concepts of Alzheimers Disease, eds P. Whitehouse, K. Maurer, and J. Ballenger (Baltimore: JHU Press), 245-256.

Prior, D., Stewart, J., and Walsh, K. (1995). Citizenship: Community, Rights and Participation. London: Pitman Publishing.

Reichertz, J. (2007). "Abduction. The logic of discovery of grounded theory," in The Sage Handbook of Grounded Theory, eds A. Bryant and K. Charmaz (Los Angeles: SAGE), 214-228.

Robinson, L., Hutchings, D., Corner, L., Finch, T., Hughes, J., Brittain, K., et al. (2007). Balancing rights and risks - conflicting perspectives in the management of wandering in dementia. Health Risk Soc. 94, 389-406. doi:10.1080/13698570701612774

Rommes, E., van Oost, E., and Oudshoorn, N. (1999). Gender and the design of a digital city. Inf. Technol. Commun. Soc. 2, 476-495. doi:10.1080/136911899359510

Rudman, S. (1997). Concepts of Persons and Christian Ethics. Cambridge: Cambridge University Press.

Schiøtz, A. (2003). Folkets helse - landets styrke 1850-2003 [Eng Translation: The Health of the People - the Strength of the Country 1850-2003]. Oslo: Universitetsforlaget.

Schot, J., and De la Bruheze, A. A. (2003). "The mediated design of products, consumption and consumers in the twentieth century," in How Users Matter. The Co-Construction of Users and Technology, eds N. Oudshoorn and T. Pinch (Cambridge: MIT Press), 229-247.

Shotter, J. (1993). "Psychology and citizenship: identity and belonging," in Citizenship and Social Theory, ed. B. S. Turner (London: SAGE), 115-139.

Sixsmith, A. (2013). "Technology and the challenge of aging," in Technologies for Active Aging, ed. A. Sixsmith (New York: Springer), 7-25.

Sixsmith, A., and Gutman, G. (eds) (2013). Technologies for Active Aging. New York: Springer.

Swidler, A. (1986). Culture in action: symbols and strategies. Am. Sociol. Rev. 51, 273-286. doi:10.2307/2095521

Swidler, A. (2006). Talk of Love: Howculture Matters. Chicago: University of Chicago Press.

Topo, P. (2009). Technology studies to meet the needs of people with dementia and their caregivers: a literature review. J. Appl. Gerontol. 28, 5-37. doi:10.1177/0733464808324019

Wang, W., and Moyle, W. (2005). Physical restraint use of people with dementia: a review of the literature. Aust. J. Adv. Nurs. 22, 46-52.

Whitlatch, C. J., Feinberg, L. F., and Tucke, S. S. (2005). Measuring the values and preferences for everyday care of persons with cognitive impairment and their family caregivers. Gerontologist 56, 370-380. doi:10.1093/geront/ 45.3.370

Wilkinson, H. (ed.) (2002). The Perspectives of People with Dementia: Research Methods and Motivations. London: Jessica Kingsley Publishers Ltd.

Winner, L. (1980). Do artifacts have politics? Daedalus 109, 121-136.

Woods, R. (2001). Discovering the person with Alzheimer's disease: Cognitive, emotional and behavioural aspects. Aging Ment. Health 5, 7-16.

Woolgar, S. (1990). Configuring the user: the case of usability trials. Sociol. Rev. 38, 58-99. doi:10.1111/j.1467-954X.1990.tb03349.x

World Economic and Social Survey. (2007). Development in an Ageing World. New York: United Nations.

Conflict of Interest Statement: The author declares that the research was conducted in the absence of any commercial or financial relationships that could be construed as a potential conflict of interest.

The reviewer $\mathrm{AB}$ and handling Editor declared their shared affiliation.

Copyright $\odot 2018$ Bergschöld. This is an open-access article distributed under the terms of the Creative Commons Attribution License (CC BY). The use, distribution or reproduction in other forums is permitted, provided the original author(s) and the copyright owner are credited and that the original publication in this journal is cited, in accordance with accepted academic practice. No use, distribution or reproduction is permitted which does not comply with these terms. 